\title{
The Forgotten Indian Pioneers of Fingerprint Science: Fallout of Colonialism
}

\author{
G S Sodhi* and Jasjeet Kaur**
}

(Received 14 April 2018; revised 19 May 2018)

\begin{abstract}
In the last decade of nineteenth century, two Indian police officers, Sub-Inspectors Azizul Haque and Hem Chandra Bose played a key role in advancement of the science of fingerprints. The so-called Henry's System of Fingerprint Classification was actually worked out by them. The world's first fingerprint bureau was set up at Calcutta (now Kolkata) in 1897 mainly by their efforts. In addition, Bose invented the first telegraphic code system for fingerprints and published it in 1916. Bose also devised the first single digit fingerprint classification system in 1927. The then British government reciprocated the sagaciousness of Haque and Bose by awarding to each of them an honorarium of Rs. 5000/- and by conferring the titles of Khan Bahadur and Rai Bahadur, respectively on them (After India became free these decorations were rendered meaningless, for all titles were abolished under an Act of Constitution). However, this is not enough. Justice has been denied to Haque and Bose. Now that the colonial clouds have dispersed, it is pertinent to highlight the contribution of these police officers so that they may officially be recognized as pioneers of the science of fingerprinting.
\end{abstract}

Key words: Azizul Haque, Bengal Bureau, Classification system, Fingerprints, Hem Chandra Bose, Henry system, Telegraphic code.

\section{INTRODUCTION}

Whether one believes in the theological origin of man or goes with the anthropological school of thought, there can be no doubt that each person is individualized by his or her fingerprints (Lambourne, 1984, pp. 60-64). Today, fingerprint individuality is accepted and taken for granted all over the world, but only when we go back into the history of this discipline do we realize that Indians knew about the relevance and significance of fingerprinting before any other civilization had an inkling of it. Since the dawn of recorded history, till the present times, Indians have consistently studied and researched this branch of knowledge, traversing from initial speculation, through interpretation, to its development into the most perfect system of identification (Sodhi and Kaur, 2013).

During the 1890s, two officers of the Bengal Police, Sub-Inspectors Azizul Haque and Hem Chandra Bose worked out a mathematical formula for classifying fingerprints. This formula was soon adopted by all the nations across the globe for cataloguing criminal record. Unfortunately, due to the imperialist policies of the colonial rulers, the Indian policemen were sidelined and their English officer, Sir Edward Richard Henry shrewdly gave his name to the classification methodology.

The present communication has been written with two aims: Firstly, to highlight that the science of fingerprinting has always been a

\footnotetext{
* Forensic Science Unit, S.G.T.B. Khalsa College, University of Delhi, Delhi-110007, Email: sodhigs1@rediffmail.com

**Department of Chemistry, Shaheed Rajguru College of Applied Sciences for Women, University of Delhi, Vasundhara Enclave,

Delhi-110096
} 
part of Indian culture and civilization and secondly, to give due credit to the Indian police officers who, despite their pioneering and innovative work on fingerprints, never got the recognition they deserved.

\section{Classification System for Fingerprints}

On June 12, 1897, the Council of the Governor General of India gave consent to the report of a committee which suggested that henceforth fingerprints should be used for classification of criminal record. The report emphasized that the method of fingerprinting was simple, cost-effective and more accurate than the anthropometric technique being used earlier (Brooker, 1977).

In the same year the first Fingerprint Bureau of the world was inaugurated at Calcutta (now Kolkata). Named, Bengal Bureau, it was housed in Writers Building. The criminal record at this bureau was filed by the so called Henry System of Fingerprint Classification, named after Sir Edward Richard Henry, Inspector General of Police, Lower Provinces, Bengal. Today, nearly all the nations of the world follow Henry's method for maintaining criminal record (Berry, 1991, pp.138).

On July 12, 1900, Lord Beeper, the Chairman of the Commission appointed by the Secretary of State to review the classification method asked Henry: 'Is this system an invention of your own?' 'Yes', replied Henry (Identification of Criminals Committee, 1900).

It was not. The system was actually invented by Sub Inspectors Azizul Haque and Hem Chandra Bose (Fig.1), while Henry, being their superior and being an English officer - shrewdly gave his name to it.

In 1899 , Henry read a paper on the classification of criminal record at Dover (England) before an assembly of the British
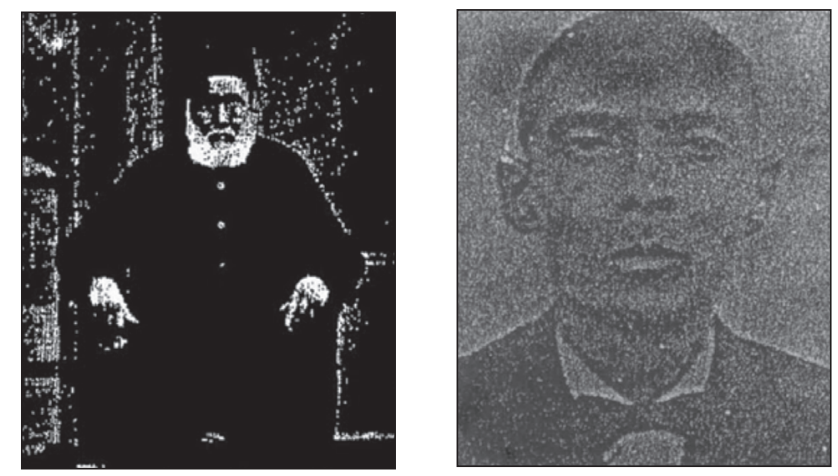

Fig. 1. Azizul Haque (left) and Hem Chandra Bose (right)

Association for the Advancement of Science (Lambourne, 1984, pp. 60-64). He did not acknowledge the role played by Haque and Bose in devising the system. In 1900, the Government of India sponsored the publication of Henry's paper in enlarged form. It was entitled, 'Classification and uses of Fingerprints'. Subsequently, Her Majesty's Stationery Office in England published numerous editions of the book. No word of thanks for Haque and Bose appears in any of the editions.

It is alleged that Haque and Bose used to tell their confidants that Henry could not even understand the system when it was patiently explained to him. They could not have done anything beyond that. In 1900, native Sub Inspectors of Police had no channel of reprisal against a British Inspector General nor would a high official doubt that a junior, and that too an Indian, could file a representation against him (Haylock, 1979).

However, in the early 1920s, Haque did represent his case to the government, although the way he did can hardly be called a representation. The whole issue arose when in 1924, Haque received the title of 'Khan Bahadur' and Henry, while congratulating him, remarked, 'I wish they had at the same time given you a jāgìr (a piece of land). On his retirement as Deputy Superintendent of Police and Honorary Magistrate, Haque wrote an application dated March 3, 1925 to the 
Governor of Bihar and Orissa (Home Department Proceedings, 1925):

Your humble memorialist's prayer is that in consideration of his loyal services, especially in the matter of the adaptation of the Finger Print System to practical use....Your Excellency's benign Government may consider your humble memorialist's case with a view to the grant of $j \bar{a} g \bar{\imath} r$.

Haque also stated in this letter that since he was confirmed as Deputy Superintendent of Police just a year and a half before his retirement, his pension had been cut down and therefore he was finding it difficult to maintain his position. In support of his case, Haque enclosed a clipping from The Statesman, dated February 28, 1925 which, in an article entitled, 'Indian Affairs in London' stated, 'A Muhammaden Sub-Inspector played an important and still insufficiently acknowledged part (in fingerprint classification)' It is also distressing to note that in this tenparagraph letter, Haque refers to himself as Your Humble Memorialist thirteen times! This is more of an appeal than a representation.

The Government of Bihar and Orissa, where Haque served his last posting, considered the application sympathetically. However, in these provinces there was no land which the government could have possibly donated to Haque. Hence it forwarded the letter to the Government of India, stating that Haque deserved to be adequately rewarded and that in place of a jog gi $r$, he may be awarded an honorarium from the central fund. J D Sifton, Esq., C.I.E., I.C.S., Officiating Chief Secretary to the Government of Bihar and Orissa further wrote (letter No. 761 PR, dated June 15, 1925):

Azizul Haque was....allowed to start research work upon a method of classifying finger prints, and after months of experiment he evolved his primary classification which convinced Sir E R Henry that the problem of providing an effective method of classifying fingerprints could be solved. Thereafter the secondary and other classifications were evolved and the Khan Bahadur played an important role in their conception (italics ours).
Sifton also stated that in March 1897, Haque appeared before the committee of experts constituted at the request of Henry to test scientifically the anthropological and finger print system. He was put to all possible tests by the committee. However, neither the Government of India nor the Government of Bengal could confirm whether Haque actually appeared before the committee.

When this letter was referred to D Petrice, Director, Intelligence Bureau, it created an element of doubt. On July 13, 1925, Petrice wrote:

There can be no doubt whatever that the present system of classification of finger-prints was a scientific discovery of great value and has been adopted all over the world. Whether Khan Bahadur Azizul Haque took as prominent a part in evolving it as is claimed for him is, however, a matter on which I have no information. He is not mentioned in Sir Edward Henry's own book, and in the history of the finger print system as given in the Encyclopedia Britannica, Sir E. Henry is quoted as the inventor....

It also created an element of surprise for Petrice further wrote:

If the Khan Bahadur rendered as valuable services as are alleged as long ago as 1893, it is curious that his claims to special recognition should have been so belatedly represented.

This situation arose because so long Henry was in India he did not speak or write a word about the contribution of Indian officers to the fingerprint classification system. Petrice then referred the letter to the Government of Bengal, since Haque was with Bengal Police when the classification formula received accreditation. L Birley, Chief Secretary to the Government of Bengal replied back on November 30, 1925 (letter No. 4382 PI):

The key (plate) referred to in page 73 of Sir Edward's book entitled Classification and Uses of Finger Prints is attributed to the Khan Bahadur and this key may have suggested the arithmetical rule for determining primary classification which is the method in use at present. 
Apart from this the Government of Bengal could not shed any light on Haque's role. It therefore suggested that the case may be referred to Henry himself. Henry endorsed the grant of honorarium to Haque. In a letter dated May 10, 1926, he wrote to P H Dumbel, the then Secretary of the Services and General Department, India Office:

...I wish to make clear that, in my opinion, he (Haque) contributed more than any other member of my staff and contributed in a conspicuous degree to bringing about the perfecting of a system of classification that has stood the test of time and has been accepted by most countries. As in most research enquires, results were achieved by team work.

One wonders why Henry, after a lapse of 30 years, became considerate towards Haque. It is commonly believed that two factors were responsible for change in Henry's attitude. Firstly, Haque (and Bose too) had risen to the rank of Deputy Superintendent of Police and could, therefore, assert himself. Secondly, by 1920s, the colonial grip was becoming loose. These may be true. However, there was another reason for Henry turning soft and, we feel, that this was more important. Four years earlier, Henry had spoken of Haque's contribution to F W Duke, an officer at India Office, Whitehall. Duke, in turn, wrote a letter on January 25, 1922, to Sir Havilland Le Mesurier, Acting Governor of Bihar and Orissa in which he stated:

\begin{abstract}
Azizul Haque devised the classification which is now in force not only in India but practically throughout the civilized world. It may have required no exceptional talent; if not done by him, the same, or an equivalent, might have been done later by someone else, but the fact remains that it was devised by him, has not been superseded and its use is world-wide (italics ours).
\end{abstract}

When Henry was consulted on Haque's honorarium, a copy of this letter was also sent to him. It was now not possible for Henry to retrace his steps. At the time of final approval of honorarium, the Home Department noted:

\begin{abstract}
It appears from the information now received that he (Haque) was Sir Edward Henry's principal helper in perfecting the scheme and that he actually himself devised the method of classification which is in universal use. He thus contributed most materially to a discovery which is of world-wide importance and has brought a great credit to the police of India (italics ours).
\end{abstract}

In his letter to Dumbel (dated May 10, 1926), Henry also wrote: 'In addition to being indebted to Khan Azizul Haque, I was indebted to some of his colleagues but, to what extent I cannot after the lapse of nearly 29 years specify more exactly'. However, Henry contradicted himself when consulted on Bose's contribution to the system. Four years later he wrote (Home Department Proceedings, 1929):

The Rai Bahadur....has devoted the whole of his official life to perfecting the methods by which search is facilitated and as his labours have contributed materially to the success achieved he is entitled to great credit.

This shows that all along Henry was aware of the contribution which Haque and Bose rendered to the fingerprint system, but he spoke up only when asked to do so. The contribution of Bose to the science of fingerprinting is best summed up in a communication (No. 650 PI, dated February 5, 1929) from the Government of Bengal to the Government of India, Home Department. It stated:

During his long service in the Bengal Bureau he (Bose) acquired unique knowledge of the science and introduced various improvements in the methods of sub-classifying finger impressions of which the following are deserving of special mention:- a) The method of comparing imperfect impressions containing only a few naked ridges; b) The sub-classification by the numerical method; c) The method of estimating the probability of fixing identity by the ridge characteristics; d) The sub-classification of the accidental type; e) The improved system of indexing; f) The introduction of a telegraphic code for finger impressions (Home Department Proceedings, 1917); g) The classification system for a single digit impression (Bose, 1927). 
Going by this communication it is evident that Bose contributed more to the subject of fingerprints than Haque. This has also been indicated in a note dated February 28, 1929 recorded by $\mathrm{P} \mathrm{C}$ Bamford of the Intelligence Bureau:

I know Rai Hem Chandra Basu (Bose) Bahadur very well, and it would be impossible to find a stronger protagonist of the fingerprint system. His open idea was to make it a success....Hem Chandra Basu (Bose) not only did his share in the original introduction of the finger print system all over India, but continued, throughout his whole service, to devote himself to this particular work, and for this reason I consider that his case for an honorarium is better than that of Khan Bahadur Azizul Haque....(italics ours).

By saying so Bamford was merely corroborating the recommendations of the Government of Bengal:

The Khan Bahadur, it is understood, was associated with this work only for a period of five years when the system was in its infancy. The Rai Bahadur has, on the other hand, been upgrudging in placing on record in his books the result of his long experience which has contributed much to the advancement of the science and the Governor in Council considers that an honorarium of Rs. 10,000/- might appropriately be granted to him by the Government of India. In making this recommendation His Excellency in Council is influenced by the consideration that the officer rendered exceptional service to police administration generally, not only in India as a whole but elsewhere (italics ours).

This recommendation was, however, turned down by the Government of India on the ground that Henry had said that Haque contributed more than any other member of his staff in perfecting the system of fingerprint classification. Hence the honorarium granted to any other officer had to be less than or equal to that awarded to Haque. Nevertheless, D Petrice, in a note dated March 5, 1929, wrote:

I am satisfied that he (Bose) has a clearly established claim on the generosity of the Government of India in recognition of the exceptional services which he has rendered to the Police Administration generally not only in India, but in civilized countries throughout the world. I am not so satisfied, however, that there is a case for giving him an honorarium of Rs. 10,000/-, as compared with Rs. 5,000/- previously awarded to Khan Bahadur Azizul Haque.

\section{How the Fingerprints are Classified}

Haque and Bose observed that fingerprint patterns fall into three broad groups: Arches, Loops and whorls. On analyzing the patterns of several thousand persons, the police officers found that nearly 5\% fingers have arch pattern, $60 \%$ have loop pattern and $35 \%$ have whorl pattern (Fig. 2).
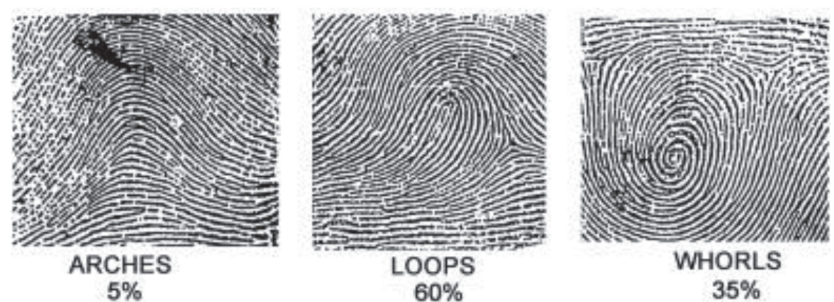

Fig. 2. Fingerprint patterns fall into three broad types: Arches, Loops and Whorls

Since statistically, too few fingers have arch design, this pattern is combined with loops. Now there are two categories of finger ridges: Loops (including arches) - $\mathbf{L}$ and Whorls - W. Next, the ten fingers are grouped into five pairs (Fig. 3).

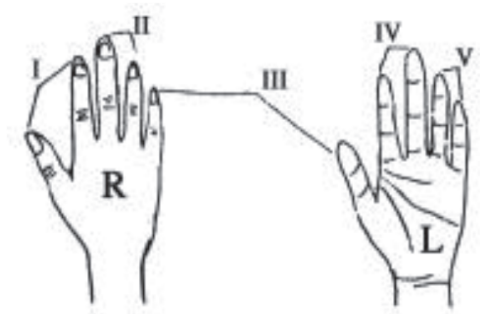

Fig. 3. For the purpose of classification, the ten fingers are grouped in five pairs

The right hand $(\mathrm{R})$ is placed left with palm down, while the left hand $(\mathrm{L})$ is placed right with palm up. The pairs are arranged in the following fraction forms (Fig. 4). 


\begin{tabular}{|c|c|c|c|c|}
\hline I & II & III & IV & $\mathrm{V}$ \\
\hline Right index & Right ring & Left thumb & Left middle & Left little \\
\hline Right thumb & Right middle & Right little & Left index & Left ring \\
\hline
\end{tabular}

Fig. 4. The pairs are arranged in fraction forms

In the first pair, consisting of right index and right thumb, there are four possibilities: a) Right index is L, right thumb is W; b) Right index is $\mathrm{W}$, right thumb is $\mathrm{L}$; c) Both are $\mathrm{L}$ and d) Both are $\mathrm{W}$.

These four possibilities exist in all the other pairs as well. Therefore, total numbers of possibilities are, $4 \times 4 \times 4 \times 4 \times 4=1024$. The figure 1024 is the square of 32 , that is, $32 \times 32=$ 1024. The criminal record room has 32 cabinets (numbered 1 to 32) and each cabinet contains 32 files (numbered 1 to 32 ). Whorls occurring in the $1^{\text {st }}, 2^{\text {nd }}, 3^{\text {rd }}, 4^{\text {th }}$ and $5^{\text {th }}$ pairs are accorded a value of 16, 8, 4, 2 and 1, respectively. Loops (including arches) are assigned a value of zero, irrespective of the pair in which they occur.

We now take representative example of a convict whose right thumb and left little fingers have whorl patterns (W), and the remaining have loop patterns (L). The filing formula may be worked out as shown in Fig. 5.

In the example given above, we add the numerators and denominators separately. We get, $1 / 16$. Adding 1 to the numerator and denominator gives $2 / 17$. The fingerprints of this person would be found in the $2^{\text {nd }}$ file of the $17^{\text {th }}$ cabinet.

The unit increase in the numerator and the denominator has been done to file the record of a person whose all ten fingers have loop patterns. In such a case, the formula would work out to be $0 / 0$. This would not find a place in the record room, for the cabinets and the files are numbered from 1 to 32 . By adding one to the numerator and the denominator, the fraction becomes $1 / 1$ and the fingerprint record of this person can be located in the $1^{\text {st }}$ file of the $1^{\text {st }}$ cabinet.

\section{INFERENCE}

Normally, alphabetical order is followed to affect classification of a specific commodity. For example, the books in a library are cataloged in alphabetical order with respect to the name of the author or the title of the text or both. It takes just a few minutes to pick out a particular manuscript from a bulk running into lakhs. The alphabetical order, however, does not work when criminal record is to be classified. The criminals have a large number of aliases. Moreover, the

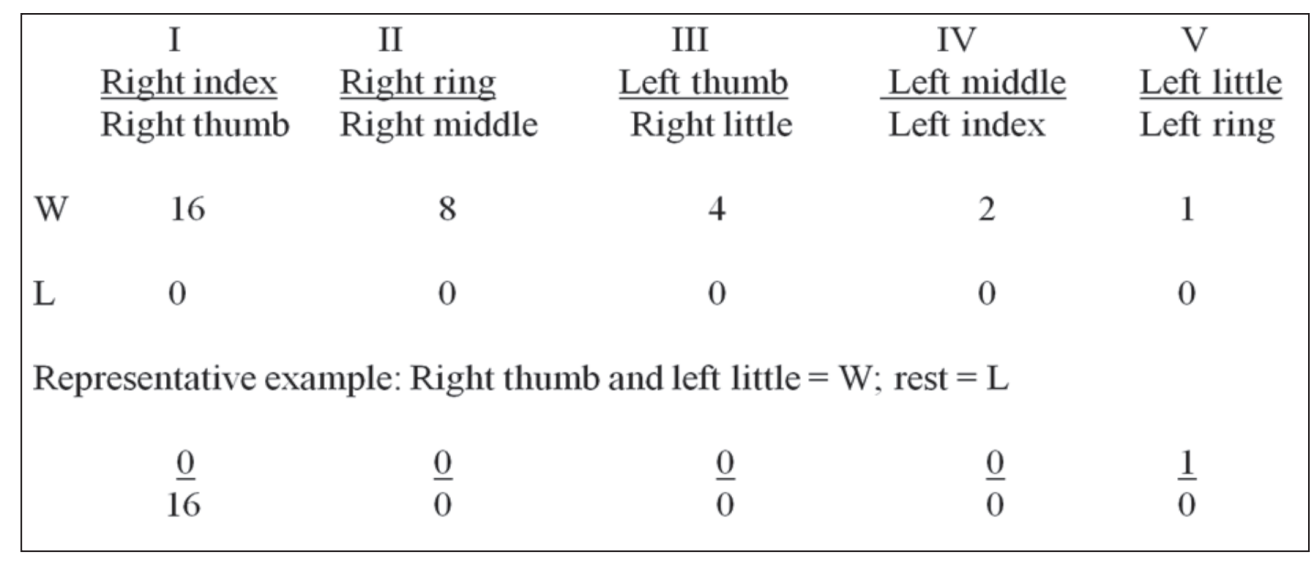

Fig. 5. Working out the Classification Formula 
criminal record cannot be supported by photographs since by changing the dress code, hair style or religion, one can easily change appearance.

Even before the fingerprint classification was devised, the experts were consentient that indexing based on a mathematical expression alone would be workable. Azizul Haque, a student of Presidency College, Calcutta, excelled in mathematics and, therefore, was picked up for the job.

Had Haque not applied for the award, his efforts towards evolving the classification formula would have gone unrecognized. And had Haque not got the honorarium, even Bose would not have been rewarded. Bose received the honorarium not because he applied for it, but because Haque's case had set a precedent. Nevertheless, the true award for a scientist, who has served a global cause, is not monetary benefit in form of honorarium, but tagging of his name with his invention. We suggest that the method be renamed as Henry-Haque-Bose system of fingerprint classification.

\section{BIBLIOGRAPHY}

Berry, J. History of Fingerprints, in H C Lee and R E Gaensslen (eds.), Advances in Fingerprint Technology, Elsevier, New York, 1991.

Bose, H C. Finger Print Companion, Gaudiya Printing Works, Calcutta, 1927.

Brooker, D R. Sir Edward Henry, Fingerprint Whorld, 3.10 (1977): 25-27.

Haylock, S E. Khan Bahadur Azizul Haque, Fingerprint Whorld, 5.17 (1979): 28-29.

Home Department Proceedings, No. F. 112/25, Police Branch, 1925.

Home Department Proceedings, No. 141-142(B), Police Branch, October 1917.

Home Department Proceedings, No. F. 14/29, Police Branch, 1929.

Lambourne, G. The Fingerprint Story, Harrap, London, 1984.

Report of Identification of Criminals Committee (1900), Her Majesty's Stationery Office, London, 1901.

Sodhi, G S and Kaur, J. Indian Civilization and the Science of Fingerprinting, Publication Division, Ministry of Information and Broadcasting, New Delhi, 2013. 